\title{
Methodology for Strategic Posture Determination of SMEs
}

\author{
Jelena Borocki ${ }^{1}$, Mladen Radisic ${ }^{2}$, Wlodzimierz Sroka ${ }^{3}$, Jolita Greblikaite ${ }^{4}$, Armenia Androniceanu ${ }^{5}$
}

\author{
${ }^{1,2}$ University of Novi Sad \\ Dositej Obradovic Square 6, 21000 Novi Sad, Serbia \\ E-mail.'borocki@uns.ac.rs, ${ }^{2}$ mladenr@uns.ac.rs \\ ${ }^{3}$ WSB University \\ 1c Cieplaka str, 41-300 Dabrowa Gornicza, Poland \\ North West University \\ 11 Hoffman str.Potchefstroom2351, South Africa \\ E-mail.wsroka@wsb.edu.pl
}

${ }^{4}$ Institute of Business and Rural Development Research

Studentu str. 11, Akademija 53361, Lithuania

E-mail.jolita19@gmail.com

${ }^{5}$ The Bucharest University of Economic Studies

Piața Romana 6, Bucuressti 010374, Romania

E-mail.armenia.androniceanu@man.ase.ro

cross'ef ${ }^{\text {http://dx.doi.org/10.5755/j01.ee.30.3.21966 }}$

Very dynamic and intense changes in the business ecosystem, as well as the need for obtaining and maintaining a competitive edge position require from enterprises to determine the most appropriate business strategies. In this respect, the determination of a strategic posture could be observed as the first step in the process of defining solid business strategy. This paper presents the methodology for strategic posture determination of SMEs. The methodology itself that is explained in detail is based on the original work of $A$. Rowe and the research has been conducted on the sample of 179 companies from an emerging market of various sizes, ownership structures and industry sectors. A modified strategic analysis tool for defining company's strategic posture (modified Strategic Position \& Action Evaluation - SPACE analysis) presented in this paper investigates the basic dimensions of external environment and enterprise itself: environment stability (ES) and industry strength (IS), as well as competitive strength (CS) and financial strength (FS). Along with the presented mathematical modeling that determines resultant vector describing the strategic posture, the paper presents the mean scores of each variable from the questionnaire results that are calculated for every strategic posture. The results obtained contribute to the precise definition of the strategic position of companies and are useful for future works related to small and medium-sized firms' strategic posture evaluation. The vast majority of sampled companies experience aggressive and competitive strategic postures with unstable resultant vector intensity.

Keywords: SMEs; SPACE Model; Strategic Posture; Strategy; Resultant Vector.

\section{Introduction}

Due to rapid changes SMEs are exposed to, they have limited time frame for the decision making process and implementation of optimal business strategies. SMEs face both external and internal (e.g. finance, people, etc.) challenges and thus there is a need for proper assessing of a firm's strategic posture. Based on current external and internal factors, SMEs should select the most appropriate business strategies allowing them to succeed and maintain their market position. The number of small and medium enterprises in the structure of the economy of the Republic of Serbia is the same as in other European developed countries. However, SMEs in the developing countries have certain limitations (in addition to insufficient financial resources) which is the reason why businesses are run differently: lack of experience in specialized areas and management, lack of practice in the application of modern and standardized strategic planning tools, decades of protection of the business environment from the operation of international companies, focus on local rather than global business, etc. However, the changes taking place in the global market have affected the developing countries as well: internationalization, networking, open innovation model, mass customization, etc.

Under such conditions, the acquisition of competitive advantage of SMEs in developing countries, and the assessment of a company's potential to change, develop and continuously monitor the changes, is one of the basic requirements in doing business. Although small and medium-sized enterprises in the developing countries have certain advantages (cheap labor, institutionalized support through government programs, some cheaper input elements, etc.), this is often not enough to compete with the competition in the international market. The competitive companies from developed countries have advanced in the 
application of certain strategic planning tools that have become part of their competencies gained through routine (Tidd et al., 2005). SMEs face a very competitive environment due to the globalization process and new technologies (Kliestikova \& Moravcikova, 2017; Sroka \& Szanto, 2018), growing role of CSR in operations (Sroka \& Vveinhardt, 2018; Kliestikova et al., 2018), inter-firm cooperation, both bilateral and multilateral (e.g. Kozma, 2017; Sebestova et al., 2017). Analyzing the involvement of states in support programs of processes of the internationalization of small and medium companies, a distribution of these programs considering the character of barriers come across by the SMEs was taken on, pointing one by one: business surroundings, the access to foreign markets, abilities of companies and financial instruments (Pietrasienski \& Slusarczyk, 2015); lack of financial resources and lack of adequate support from financial institutions (Belas et al., 2017) - which is especially important for SMEs in less developed countries.

The changes that occurred, primarily related to the speed of decision making and the speed of reaction to environmental conditions in all segments of the society, included strategic planning tools as well - combining with modern mathematical models and extending the models by exploring contemporary aspects. In the literature, numerous studies have shown the efficacy of applying strategic planning and its relation to the company's business results (Boyd, 1991; Kraus et al., 2006; Parnell et al., 2015; Suklev \& Debarliev, 2012; Gica, \& Balint, 2012; Dibrell, et al., 2014; Ghobadian, et al., 2008; Kraus, et al., 2008; Street, et al., 2017; Stonehouse \& Pemberton, 2002; Peel \& Bridge, 1998; Griggs, 2002).

A comprehensive strategic management tools and methodologies such SPACE have rarely been used in the context of research studies covering samples of SMEs from less developed economies of South Eastern Europe. Taking into consideration that SMEs encompass the majority of economic activities in emerging markets as well, it is of great importance for both business practitioners and academic communities to understand better how SMEs behave with respect to their strategic postures. Because of the lack of available literature in this domain, our work highlights the need for researching emerging markets' small and medium sized firms strategic positioning and explains the importance of using strategic analysis tools for SMEs.

This paper presents a survey that covers mainly SMEs in one developing country i.e. in the Republic of Serbia, and the objective was to define characteristic strategic positions and strategies that such companies implement. Also, the authors tried to determine whether the SPACE model (Strategic Position and Action Evaluation), a model for determining the strategic position of the company, is also applicable in the conditions of a developing country and companies of different size, type of business and ownership. In order to determine the number and content of latent classes, finite normal mixed modeling or analysis of latent classes, was conducted. In order to examine the connection between the association with one of the classes and the strategic performance of the company, $\chi 2$ test was applied.

The problem of interest in this research was to define if SMEs (micro, small and medium enterprises) are different among themselves taking into consideration their strategic posture, as well as if the value of basic dimension used in the determination of the type of strategic performance of the company - Financial Strength (FS), Competitive Strength (CS), Environment Stability (ES) and Industry Strength (IS) - could become the base for classification into clusters. Also, the purpose of this study is to investigate if there are potential differences between the size of the company and the type of strategic performance, as well as if the activity of the company is related to the strategic performance.

Structure of the paper is as follows: the first part presents theoretical background of the applied strategic planning model, then, the applied methodology is presented, as well as the research results and discussion. After the conclusion, there is a list of used references.

\section{Literature Review}

Strategic planning involves the application of certain tools for the analysis of the situation and planning of the reaction (response) to the existing situation - appropriate strategy development (Brews \& Hunt, 1999; Malekpour et al., 2015; Walker et al., 2013). Although there are some studies on the use of recognized tools, methodologies, and strategic planning models, there is not enough experience in the application of these tools in the developing countries (Grant, 2003). No matter how strategic planning tools have been recognized, they are insufficient in the implementation phase of a particular strategy and goals (Miller \& Cardinal, 1994; Kraus et al., 2013).

Some examples of strategic planning in the developing countries can be found with the following authors (Derbaliev \& Trpkova, 2011). Undoubtedly, the results of Mintzberg (Mintzberg, 1994), together with some other authors, are also significant in the field of strategic planning (Kimemia et al., 2017; Nomsa \& Tebogo, 2017; Fuad, 2001).

The Strategic Position and Action Evaluation (SPACE) analysis is in many ways similar to other tools used in strategic planning (SWOT, BCG matrix, etc.) primarily due to its similar purpose of application. The diversity has been achieved in several aspects: comprehensiveness simultaneous analysis of the external and internal environment with values of a predefined set of factors of basic dimensions; hierarchical structure of the model; different aspects of factors and the possibility of finding the critical ones. SPACE analysis is also characteristic for its ability to choose an appropriate strategy based on an existing strategic performance that is in accordance with the set theoretical backgrounds (Porter, 1979; Drucker, 1986). Also, based on a defined strategic approach, it is possible to set the basis for the company's strategic development plan setting the goals that should be directed to elimination of critical factors for maintaining or improving the existing strategic position.

The results of some scientific papers indicate that the SPACE model (Saeed et al., 2013) can be used as a strategic planning tool for different enterprises (operating in different business industries) and in different countries (Kazemi, et al., 1998; Bafandeh et al., 2012; Kash \& Deshmukh, 2013; Li \& Hamblin, 2003; Nouri et al., 2008; Benson \& Henderson, 2011; Sukcharoensin, 2018). The advantage of the SPACE model is a simultaneous analysis of equally important external and internal environment factors. The application of the model provides top-level managers with 
better understanding of the environment in which the enterprise operates, and it helps them to focus on recommended and adequate strategies (even though it is limited set of strategies). The problem of choosing a strategy is often seen as the optimization problem - but not regarding the search for optimal solution for limitations, but rather as the problem of achieving a sustainable advantage over competitors. The optimal strategy of the company is the one that emphasizes the characteristics - advantages - of an enterprise. The SPACE model provides not only adequate strategic posture: it gives an adequate basic for creating strategic plan and choosing an appropriate strategy. Specific corrective measures in the SPACE matrix model can be identified on the basis of the outline plans and the subsequent profiles, as well as on their comparison. The author David (David, 2011) also believes that the SPACE tool is highly useful in the process of strategy defining. Main task of corporate strategy is not to describe the current stateof-art, but to identify and explore core competencies that must be added (Rajesh, et al., 2008). Although Porter suggests that an enterprise should be focused on one strategy, the latest research (Hlavacka, et al., 2001; Allen \& Helms, 2006; Kim, et al., 2004; Valaei, et al., 2017; Brunswicker \& Vanhaverbeke, 2015; North \& Varvakis, 2016) have shown that strategy formation also requires a company to be creative and innovative, and that the strategy needs to be defined according to the company's features and by combining core competencies.

The advantage of SPACE model is simple presentation of the company's strategic position through graphic representation of the resulting vector which summarizes the value of all analyzed factors. In the Cartesian coordinate system, the resultant includes the summarized values of the four basic dimensions: Competitive Strength (CS) and Industry Strength (IS) - representing the values on $\mathrm{X}$ axis and ranging from 0 to -6 (CS) and from 0 to 6 (IS); and Financial Strength (FS) and Environmental Stability (ES) representing the values on $\mathrm{Y}$ axis which can range from 0 to -6 (ES) and from 0 to 6 (FS). The resulting value of each of the four basic dimensions is obtained as the average value of all the selected factors which are used for this dimension evaluation.

The graphically presented model shows that the strategic position of the company can have the resulting vector in one of the four quadrants that define: aggressive, conservative, defensive and competitive strategic approach (Figure 1).

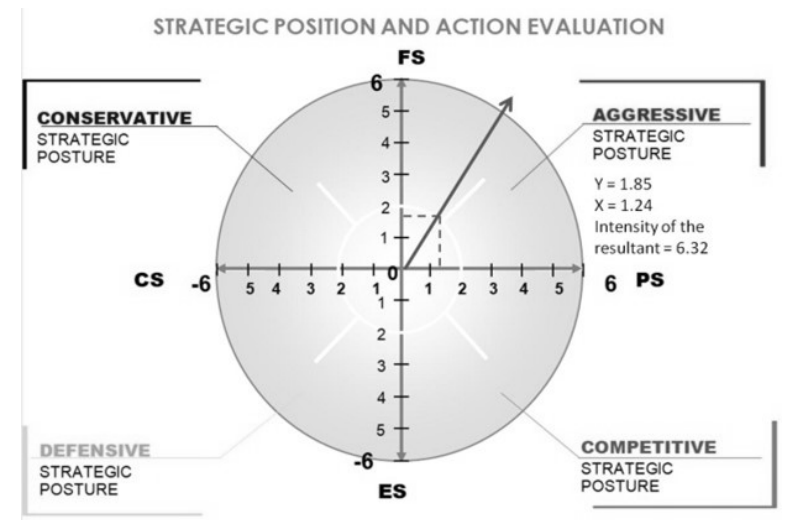

Figure 1. Graphical Presentation of the SPACE Model
In addition to a single graphic representation of the company's strategic position, some authors (Afriani, et al., 2012) suggest using this model to determine an adequate strategy where the SPACE model is used in the second of the three proposed stages: 1. Input, 2. Matching and 3. Decision stage. The use of the SPACE model at this stage is encouraged by the idea that adequate strategies are formed to match the resources and skills of the company with respect to opportunities and risks from the external environment (Robert, 1991). In addition to this model, SWOT Matrix, BCG Matrix, IE Matrix and QSPM are also proposed. According to the author, each of the proposed models/matrices can significantly improve the quality of strategic decisions when choosing an appropriate strategy, but they should not be the only criterion for the choice.

\section{Methods}

Since the SPACE model was first launched for assessment of the company's strategic position, new versions of the model have emerged, aligned with new findings in other areas (mathematics), changes in the areas of strategic planning and new requirements that companies have in a turbulent and rapidly changing environment. Rowe et al. (1994) attempted to overcome some limitations of the model by creating the SUPER SPACE model, which implies the addition of new aspects: evaluation of relative importance of each factor and assessment of the company's ability to achieve the estimated level of significance (Rudder \& Louw, 1998).

This paper presents the modification of basic SPACE model achieved by creating a comprehensive questionnaire with more sets of factors, and by introducing a twodimensional assessment of the selected factors. The questionnaire designed to determine the strategic position of a company is different from the initial model created by Rowe et al. (1994) because all the factors of the model are presented from the aspect of their values and significance for company's business. A seven-point (for value assessment), that is, nine-point Likert scale for significance assessment was used for the evaluation. Examples of questionnaire segment are presented in the Figure 2 grading of value, and Figure 3- evaluation of significance.

101 Available technological knowledge

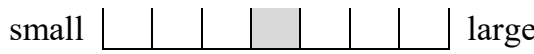

Figure 2. Likert scale - value assesment

101 Available technological knowledge

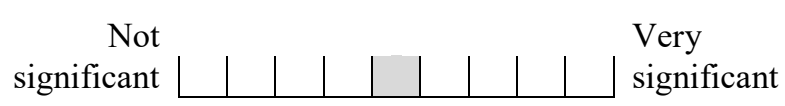

Figure 3. Likert scale - significance assesment

Certain factors could not be evaluated directly so they were divided into indicators; therefore, the factor value was affected by the values of individual indicators that build its structure. Some of the earliest factors have been modified or grouped, some are derived into indicators that indirectly measure the factor value in line with the characteristics of SMEs in the Republic of Serbia. A matrix scale is used for 
factors which value is indirectly evaluated through certain indicators. The display of the hierarchical structure of the SPACE model is presented in Figure 4.

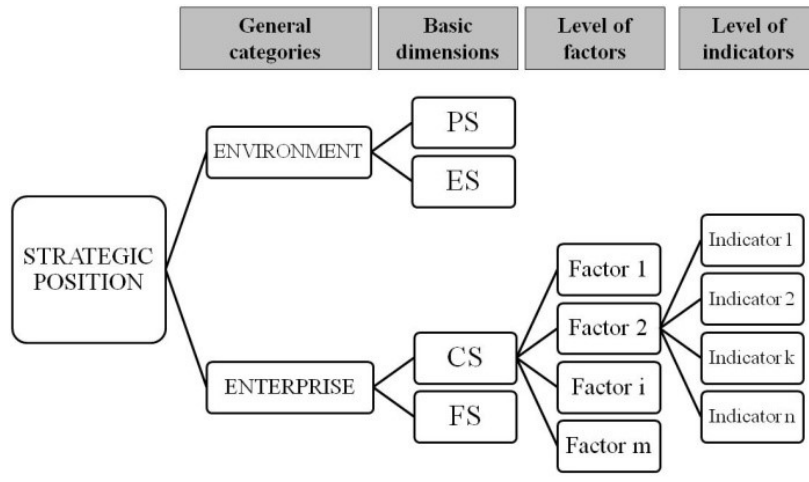

Figure 4. Hierarchical Structure of the SPACE Model

The survey has started at the end of 2017, and lasted almost ten months. The companies were randomly selected. In the existing sample of companies which belong to the SMEs sector, special aim was at balancing the sample structure. The sample contains $24.58 \%$ micro, $29.05 \%$ small and $26.26 \%$ medium-sized enterprises. The questionnaire was distributed and filled in through direct contact with respondents. The values and significance were assessed by owners of the companies, that is, managers in certain segments of organizations (marketing director, financial director, sales manager, etc. - every person in his/her field of expertise) depending on the presence of this function in a company.

Phase 1 - preparing:

1) Defining all necessary elements for applying model for determine company strategic position.

2) Drawing up the list of indicators and designing questionnaire for collecting data.

3) Making a team of experts (internal and external) who will evaluate value and weight of every factor and indicator; informing them with the procedure.

Phase 2 - assessment factors and indicators - current strategic position:

4) Process of assessment value and weight of every factor and/or indicator; eliminating disregarded variables and evaluating value of remanded indicators.

5) Decoding filled questionnaires, scaling variables, calculating and normalizing basic dimensions of company strategic position.

6) Analyzing critical factors and basic dimensions of company strategic position (for main business and company in hole).

7) Defining direction and intensity of main vector (obtained as a result of mathematical procedures for each basic dimension).

8) Defining graphical presentation of company strategic position (for main business and company in hole).

9) Formulating the assessment of company strategic position and giving suggestions of acceptable strategic posture.

Phase 3 - changing values - desirable strategic position:

10) Assessing possible differences between current and desirable strategic position.
11) Analyzing possibilities how to change current company strategic position through changing final values of basic dimensions from internal environment: $\mathrm{CS}$ and FS.

12) Applying Pareto Law and analyze of importance on basic dimension from internal environment - CS and FS.

13) Assessing level of influence on changing value of factor.

14) Defining direction and intensity of resulted vector of new company strategic position, for changed and maximum values of important factors.

15) Designing new graphical presentation for changed and maximal values (for every individual business and/or company).

16) Assessing possibilities how to reach new strategic position (with existing facilities, funds, capacities and skills of company).

Eventually, one can apply steps from 11 to 16 - process of changing values of basic dimensions from external environment: ES and IS, if is still present gap between current and desirable company strategic position.

\section{Determining the Direction and Intensity of the Resultant Vector of Strategic Position}

Having completed the evaluation of factors and indicators, that is collection of adequate data, the completed questionnaires are encoded and variable scaling, calculation, and memorizing of all basic dimensions of the strategic position of the company is performed.

In order to pursue with the mathematical calculations, it is necessary to convert the qualitative aspects into the quantitative ones. One of the most frequently used transformations of qualitative aspects into the quantitative ones is the so-called bipolar scale. This does not imply proper scaling but specific encoding of ranked qualitative variables. The evaluation of level and significance of factors/indicators is descriptive (qualitative), so they need to be converted into numerical values by means of encoding in order for the resulting values of the basic dimensions or the resultant vector to be determined. The seven-point scales (semantic differential) are presented in such a way that their left or right end represents the minimum or maximum level, which means that the factor/indicator level can be: $0,1,2$, ...., 6; the significance of the factor, which is evaluated by the eight-point scale, can be any value from the set of values: $0,0.5,1,1.5,2,2.5, \ldots . ., 4$. Considering the different maximum scale values and scale distribution, the level and significance of each factor must be normalized in order the level of accuracy to be increased according to the following equations (Eq. 1 and Eq. 2):

$$
\begin{aligned}
& \mathrm{V}_{\mathrm{r}_{\mathrm{i}}}=\mathrm{V}_{\mathrm{i}} / \mathrm{V}_{\max } \\
& \mathrm{V}_{\mathrm{i}} \in\{0,1,2 \ldots ., 6\}, \quad \mathrm{V}_{\mathrm{r}_{\mathrm{i}}} \in[0 ; 1]
\end{aligned}
$$

where:

$$
\begin{array}{ll}
\mathrm{V}_{\mathrm{i}} & - \text { level of } \mathrm{i} \text {-factor } \\
\mathrm{V}_{\max } & - \text { maximum level of any factor }
\end{array}
$$


$\mathrm{V}_{\mathrm{r}_{\mathrm{i}}} \quad$ - normalized level of $\mathrm{i}$-factor

$\mathrm{Z}_{\mathrm{r}_{\mathrm{i}}}=\mathrm{Z}_{\mathrm{i}} / \mathrm{Z}_{\max }$

$\mathrm{Z}_{\mathrm{i}} \in\{0,1,2 \ldots ., 4\}, \quad \mathrm{Z}_{\mathrm{r}_{\mathrm{i}}} \in[0 ; 1]$

where

$Z_{i}$ - significance value of i-factor

$Z_{\text {max }}$ - maximum value of significance of any factor

$Z_{r_{i}}$ - normalized value of significance of $i$-factor

The direction of the resultant vector of the strategic position of the company (Eq. 3) is obtained by the rules of vector algebra in the following order, for practical reasons:

$$
\vec{R}_{r}=\left[\vec{R}_{D 1}+\vec{R}_{D 2}\right]+\left[\vec{R}_{D 3}+\vec{R}_{D 4}\right]
$$

where:

$\overrightarrow{\mathrm{R}}_{\mathrm{D} 1^{-}} \quad$ resultant vector of the basic dimension D1 - Environment Stability

$\overrightarrow{\mathrm{R}}_{\mathrm{D} 2}$ - resultant vector of the basic dimension D2 - Industry Strength

$\overrightarrow{\mathrm{R}}_{\mathrm{D} 3}$ - $^{-} \quad$ resultant vector of the basic dimension D3 - Company's Competitive Strength

$\overrightarrow{\mathrm{R}}_{\mathrm{D} 4}$ - $^{-} \quad$ resultant vector of the basic dimension D4 - Company's Financial Strength

The projection of the resultant obtained in this way does not represent its true intensity because it is four-dimensional space. Considering the fact that the starting point of the resultant is always the coordinate beginning and the observed components of the vector have non-negative values, it can be concluded that absolute and relative intensity of the resultant can be determined as its absolute length in E4 space (Eq. 4).

$$
\begin{gathered}
\mathrm{R}^{*}=|\overrightarrow{\mathrm{R}}|=\sqrt{\sum_{\mathrm{j}=1}^{4}\left[\mathrm{R}_{\mathrm{D}_{\mathrm{j}}}-\mathrm{R}_{\mathrm{D}_{\mathrm{j}}}{ }^{(0)}\right]^{2}}=\sqrt{\sum_{\mathrm{i}=1}^{4} \mathrm{R}_{\mathrm{D}_{\mathrm{j}}}{ }^{2}} \\
\text { because } R_{D_{j}}{ }^{(0)}=0, \text { for } \forall \mathrm{R}_{\mathrm{D}_{\mathrm{j}}}, \mathrm{R}=R^{*} / \mathrm{R}_{\text {max }} \text { or } \\
\mathrm{R}[\%]=100 \bullet\left(\mathrm{R}^{*} / \mathrm{R}_{\max }\right)
\end{gathered}
$$

For each factor in the questionnaire, the GAP is calculated, which represents the difference between the maximum level and the actual level of factors:

$$
\begin{aligned}
\mathrm{GAP}_{\mathrm{i}} & =\mathrm{V} \text { max }-\mathrm{V}_{\mathrm{i}} \\
\mathrm{GAP}_{\mathrm{r}} & =\mathrm{GAP}_{\mathrm{i}} / \mathrm{GAP} \max \\
\mathrm{GAP}_{\mathrm{i}} & \in\{0,1,2 \ldots ., 6\}, \quad \mathrm{GAP}_{\mathrm{r}} \in[0 ; 1]
\end{aligned}
$$

where:

$\mathrm{GAP}_{\mathrm{i}}$ - difference between the maximum level and the actual level of $\mathrm{i}$-th factor

$\mathrm{GAP}_{\max }$ - maximum value of the GAP

$\mathrm{GAP}_{\mathrm{r}}$ - normalized value of $\mathrm{i}$-th factor's GAP
Normalization of sizes: $V_{i}, Z_{i}$, and $\mathrm{GAP}_{i}$, is done for simultaneous observation of a large number of attributes with different numerical units, i.e., to align the different range of features. Linear attribute normalization is applied, which requires division of attribute value to be divided with its own maximum value. After this transformation, the values of all attributes range in the interval $[0,1]$. The advantage of this attribute normalization is that the results are transformed in a linear (proportional) way, so that the relative order of the result values remains the same.

Then follows the calculation of the size S1, which represents the product of the normalized GAP values and significance (for each factor separately):

$$
\mathrm{S} 1=\mathrm{GAP}_{\mathrm{r}_{\mathrm{i}}} \cdot \mathrm{Z}_{\mathrm{r}_{\mathrm{i}}}
$$

where:

S1- product of normalized values of GAP and significance (for each factor of every basic dimension individually).

For every basic dimension of the SPACE model, should be calculated $R_{\mathrm{Dj}}$ :

$$
\mathrm{R}_{\mathrm{D}_{\mathrm{j}}}=\frac{\sum_{\mathrm{i}=1}^{\mathrm{n}} \mathrm{V}_{\mathrm{i}} \cdot \mathrm{Z}_{\mathrm{i}}}{\sum_{\mathrm{i}=1}^{\mathrm{n}} \mathrm{Z}_{\mathrm{i}}}, \quad \mathrm{j}=1,2 \ldots, 4
$$

These values represent the basis for the application of significance analysis. This analysis implies the definition of a significant area in which those factors can be changed, that will also affect the changes in strategic position of the company. Factors that can be changed are those on which the company has a certain impact, i.e. resources. Changing the critical factors to which the company has a high impact, changes the strategic position of the company in the planned future time period. After determine company strategic position, through applied model, if still exist gap between current and desirable strategic position, it can be defined group of factors on which company has some influence to change them (that means that company has some potential to improve their values).

\section{Results}

The research sample covers 179 companies from the Republic of Serbia with $39.1 \%$ being manufacturing companies and $60.9 \%$ service companies. Small and medium enterprises in the sample structure hold a significant share of around $79.9 \%$ (micro $-30.8 \%$, small- $39.9 \%$ and medium $29.37 \%$ ). Most of the companies from the research sample have aggressive strategic posture $(40.8 \%)$ or a competitive one $(34.6 \%)$, followed by a defensive $(18.4 \%)$ and conservative strategic postures $(6.1 \%)$. Detailed characteristics of the research sample are given in Table 1.

The most of the micro and medium enterprises have aggressive strategic posture (almost $45 \%$ ), while most of the small enterprises have competitive position (Table 2). 
Research Sample

\begin{tabular}{|c|c|c|c|}
\hline & & $\mathrm{N}$ & $\%$ \\
\hline \multirow{2}{*}{ Type of the company } & Manufacturing & 70 & 39.1 \\
\hline & Service & 109 & 60.9 \\
\hline \multirow{2}{*}{ Size of the company } & SMEs & 143 & 79.9 \\
\hline & Large companies & 36 & 20.1 \\
\hline \multirow{4}{*}{ Strategic posture } & Defensive & 33 & 18.4 \\
\hline & Aggressive & 73 & 40.8 \\
\hline & Competitive & 62 & 34.6 \\
\hline & Conservative & 11 & 6.1 \\
\hline \multirow{3}{*}{ Ownership } & Private owned companies & 143 & 79.9 \\
\hline & State owned & 36 & 20.1 \\
\hline & TOTAL & 179 & 100.0 \\
\hline
\end{tabular}

Type of Strategic Position for SMEs

\begin{tabular}{|c|c|c|c|c|c|}
\hline SMEs & Defensive position & Conservative position & Competitive position & Aggressive position & TOTAL \\
\hline Micro enterprises & 8 & 2 & 14 & 20 & 44 \\
\hline Small enterprises & 10 & 2 & 23 & 17 & 52 \\
\hline Medium enterprises & 8 & 6 & 12 & 21 & 47 \\
\hline TOTAL & 26 & 10 & 49 & 58 & 143 \\
\hline
\end{tabular}

The following diagrams (Figure. 5 to 8 ) show current strategic positions (performances) of micro, small and medium companies from the research sample based on the calculated resultant values (their coordinates - formulas 3 and 4). Similar model of description of condition/ research sample of specific group of companies is offered in the work of Benson and Henderson (Benson \& Henderson, 2005).

Different Diagrams $\rightarrow$ SPACE Postures of the Research Sample

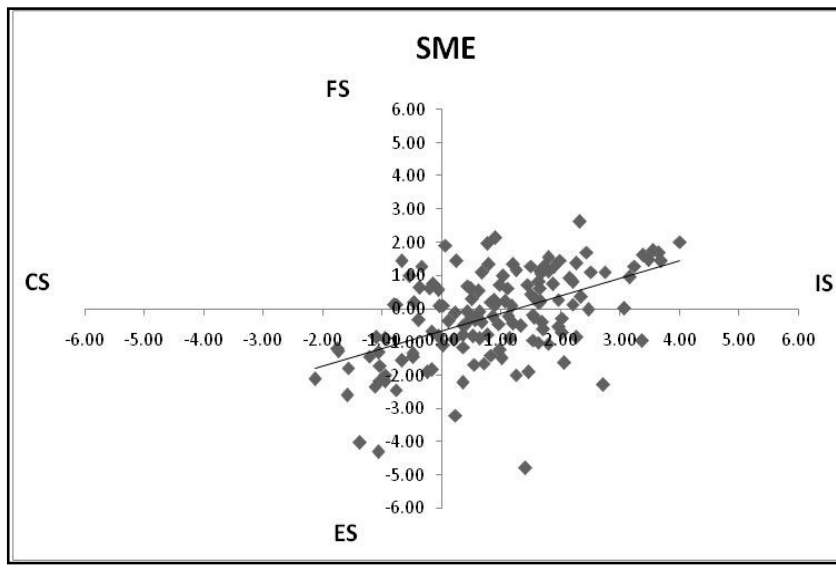

Figure 5. SPACE Plot for SME from the Research Sample

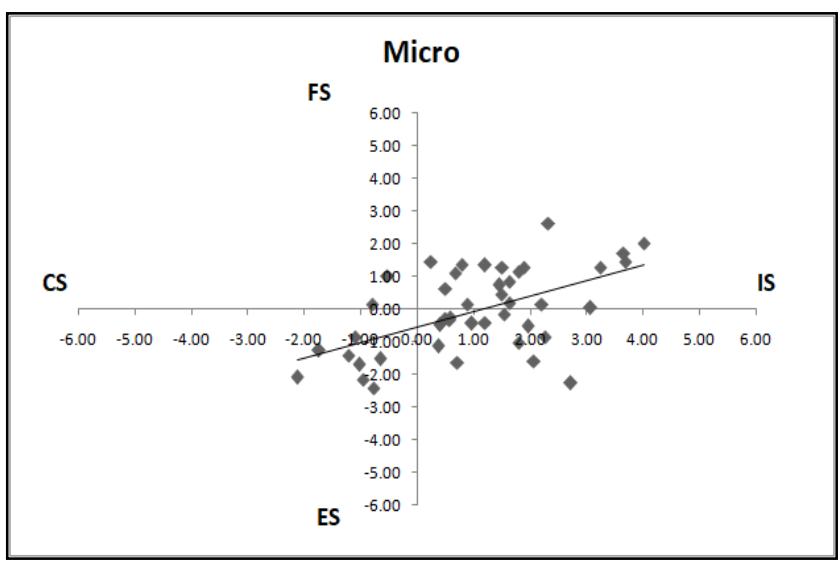

Figure 6. SPACE Plot for Micro Enterprises

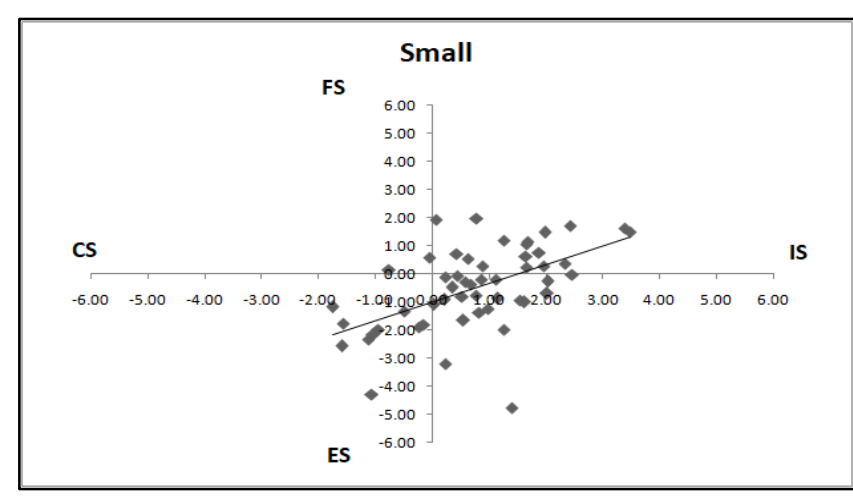

Figure 7. SPACE Plot for Small Enterprises

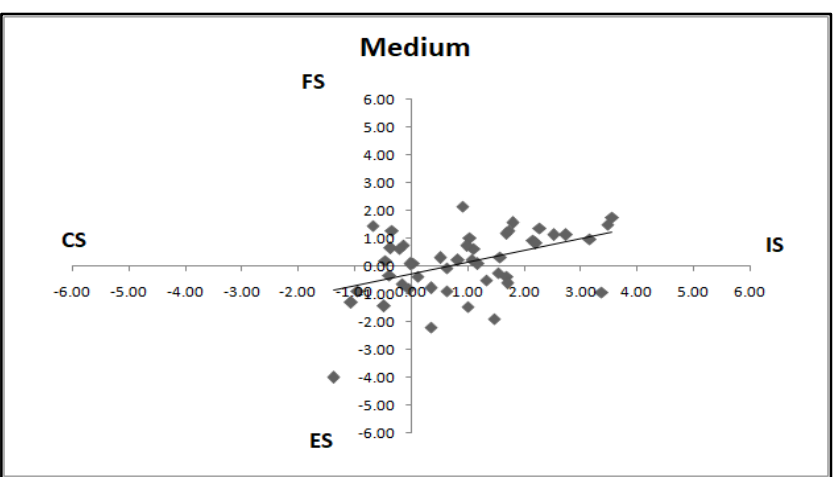

Figure 8. SPACE Plot for Medium Enterprises

\section{Description of Strategic Positions - Obtained Results}

The model applied in the research contains four basic dimensions: two dimensions assess the external environment and two assess internal environment (internal potential of the company). The Industry Strength (groups, segments) and the Environment Stability assess the economic environment, i.e. the strategic position of the entire industry branch, and the Financial Strength and the Competitive Strength of the company assess the strategic position of the company. Based on the way the model 
is designed, the basic dimensions of the model are mutually opposed so, for example, the Financial Strength may have any value ranging from 0 to 6 , while the values of Environment Stability may range from 0 to -6 . The Industry Strength potential can weaken the competitive position of the company and the Environment Stability can overcome the financial problems of the company. Based on the results obtained from the research, it can be concluded that none of them can be kept at positive level: to be more precise, even if the company has a significant financial strength, (in)stability of the external environment is still a threat.

Each of strategic performances can be linked to one of the generic strategies. This way, the aggressive strategic position is characterized by cost leadership strategy, concentric diversification and vertical integration. The competitive strategic posture (which is common in most small enterprises from the research sample) is characterized by being typical for relatively attractive industries in an unstable external environment; the company should reduce its costs and increase its financial potential.

It is obvious that present recommendations on the selected strategies cannot be accepted for the conditions of the observed developing countries. The question remains open whether the acquisition of adequate financial resources would be sufficient for improving the unstable "hostile" external environment in which there is a high probability that the technology will change as well as the demand for a product/service, and/or competitive strategy.

It was noticed that in the environment of the observed developing countries, the 'hostile' environment implied something quite different, unlike the ruling stances in the literature. The 'hostile' environment in the economy of the observed countries implied frequent changes in state legislation, regulations, prices of energy sources, etc.
Assumption that aggressive strategic position of a company (intensity) increases with rising hostility in external environment is proved by the fact that all companies from the sample showed that the external environment was uncertain and hostile and the majority of companies from the sample had that type of aggressive strategic posture.

Descriptive statistical indicators are presented in Table 4. Most values in the basic dimension Financial Strength (FS) are achieved by enterprises with aggressive and conservative approach, while the highest values in the dimensions of the Competitive Strength (CS) and Environmental Stability (ES) are achieved by enterprises with aggressive and competitive approach. The highest values on the basic dimension Industry Segment potential (IS) are achieved by companies with competitive and aggressive approach.

Based on the values presented in Table 3, it can be noticed that defensive strategic position is characterized by significant weakness (the worst position) not only because of low competitive strength ( $\mathrm{CS}=-3.12)$, but also because of low environment stability $(\mathrm{ES}=-3.97)$. Aggressive strategic position is characterized by the most stable environment ( $\mathrm{ES}=-2.92)$ and highest financial strength (FS $=3.91$ ). Competitive and defensive positions are characterized by unstable external environment ( $\mathrm{ES}=-3.96$ and -3.97 , respectively), but the financial strength is different: $\mathrm{FS}=3.02$ for competitive and 2.43 for defensive strategic position, and there is also a significant difference in values of competitive strength (CS), that is, for the defensive strategic approach with significant difference in the values of competitive potential (CS), that is, the potential of business sector - IS.

Table 3

Distinctions between Each Position of SPACE Analysis

\begin{tabular}{|l|l|c|c|c|c|}
\cline { 3 - 6 } \multicolumn{2}{c|}{} & Financial Strength (FS) & Competitive Strength (CS) & Environment Stability (ES) & Industry Strength (IS) \\
\hline \multirow{2}{*}{ DEFENSIVE } & Mean & 2.43 & -3.12 & -3.97 & 2.16 \\
\cline { 2 - 6 } & Std.Dev. & 0.81 & 0.67 & 0.62 & 0.58 \\
\hline \multirow{2}{*}{ CONSERVATIVE } & Mean & 3.50 & -2.64 & -3.07 & 2.20 \\
\cline { 2 - 6 } & Std.Dev. & 0.55 & 0.77 & 0.58 & 0.72 \\
\hline \multirow{2}{*}{ AGGRESITIVE } & Mean & 3.02 & -2.04 & -3.96 & 0.53 \\
\cline { 2 - 6 } & Std.Dev. & 0.71 & 0.65 & -2.92 & 0.56 \\
\hline \multirow{3}{*}{ TOTAL } & Mean & 3.91 & -1.70 & 0.51 & 0.64 \\
\cline { 2 - 6 } & Std.Dev. & 0.50 & -2.14 & -3.48 & 3.05 \\
& Mean & 3.30 & 179 & 179 & 179 \\
\cline { 2 - 6 } & N & 179 & 0.83 & 0.74 & 0.79 \\
\cline { 2 - 6 } & Std.Dev. & 0.86 & & & \\
\hline
\end{tabular}

\section{Clusters or Classes}

In order to determine the number and content of latent classes, a finite normal mixed modeling, or analysis of latent classes (LCA), was carried out in the R. McLust package (Scrucca et al., 2016). The above procedure generates solutions with one up to nine latent classes that differ in distribution (spherical, diagonal, ellipsoidal), volume (variable or equal), shape (variable or equal), and orientation (parallel with coordinate axes, variable or equal). Based on the Bayesian Information Criterion (BIC), an optimal solution is selected. The above criterion is most suitable, since it enables direct comparison between different solutions (Scrucca et al., 2016; Fraley \& Raftery, 2002). The variables used for the analysis of latent classes were the basic dimensions of the SPACE model which are used in the determination of the type of strategic performance of the company: Financial Strength (FS), Competitive Strength (CS), Environment Stability (ES) and Industry Strength (IS).

As the most optimal solution $(\mathrm{BIC}=-1661.315)$, three spherical latent classes of different volume are distinguished. The results are shown in the Figure. 9. The first selected class $(\mathrm{N}=$ $40 ; 23.5 \%$ ) are enterprises with the lowest values on Financial 
Strength (FS) and Environment Stability (ES) dimensions, but also with the least expressed, although positive, values in the Competitive Strength (CS) dimension and Industry Strength (IS). The second distinguished class $(\mathrm{N}=10 ; 5.4 \%)$ are companies with the highest values in the Competitive Strength (CS) and Industry Strength (IS), but also with the most expressed, although negative, values in the Financial Strength (FS) and Environment Stability (ES). The third class (129; 71.1 $\%$ ) are enterprises with all four dimensions moderately expressed compared to the first and second class.

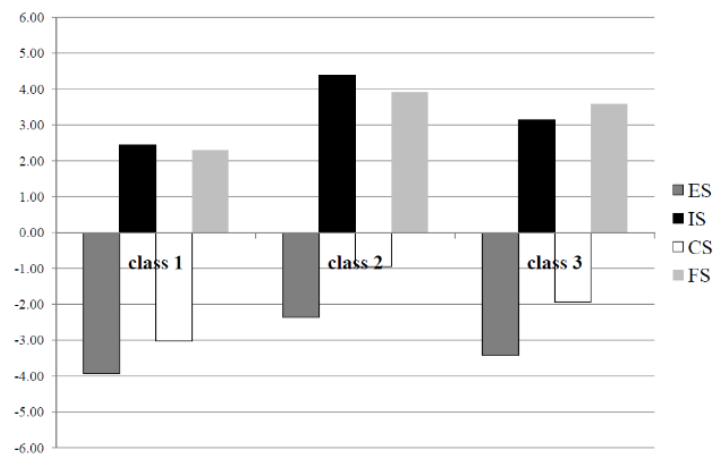

Figure 9. Characteristics of the Selected Latent Classes

Correlation between these classes and strategic approach of the company is strong and significant.

In order to examine the connection between the three classes and strategic performance of the company, $\chi 2$ test was applied. The relationship between the variables is statistically significant $(\chi 2(6)=116.24, \mathrm{p}<.001)$ and moderately strong $(\mathrm{C}=0.62, \mathrm{p}$ $<.001)$. Companies of the first class usually have a defensive performance, while companies of the second class most often have an aggressive approach. Third-class companies have an aggressive or competitive performance. It can be also noticed that the smallest number of companies have conservative performance, which is very rarely represented among isolated classes. The results are presented in Table 4.

Table 4

Relation between the three Classes and Present Performance of the Company

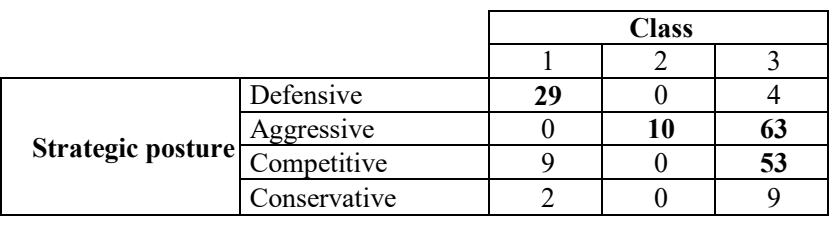

When compared based on the type of strategic performance, the production and service companies do not show the difference, that is, the activity of the company is not related to the strategic performance.

It was also examined whether there are potential differences between the size of the company and the type of strategic performance, and it was concluded that there were no differences: micro, small and medium enterprises (on the one hand) and large enterprises (on the other hand) apply equally these strategic approaches, that is, the type of strategic performance is not predetermined by the size of the company.

$\chi 2$ test was applied in order to examine the relationship between the company's activity (production or service) and the type of company's strategic performance. The relationship between the mentioned variables is not statistically significant $\left(\chi^{2}(3)=4.734, \mathrm{p}=0.19\right)$.

In order to examine the relationship between the size of the enterprise (small or large) and the type of company's strategic performance, $\chi 2$ test was applied. The correlation between these variables is not statistically significant ( $\chi 2$ (3) $=0.89, \mathrm{p}=0.82$ ).

The $\chi 2$ test was applied in order to examine the relationship between the type of enterprise and ownership (state owned or private) and type of company's strategic performance. The relationship between the mentioned variables is not statistically significant $(\chi 2(3)=4.66, p=$ 0.22 ) - Table 5 .

Table 5

Relation between the three Classes and Type of Ownership

\begin{tabular}{|c|c|c|c|}
\cline { 3 - 4 } \multicolumn{2}{c|}{} & \multicolumn{2}{c|}{ Ownership } \\
\cline { 3 - 4 } \multicolumn{2}{c|}{} & Private & State owned \\
\hline \multirow{3}{*}{ Class } & 1 & 24 & 16 \\
\cline { 2 - 4 } & 2 & 9 & 1 \\
\cline { 2 - 4 } & 3 & 110 & 19 \\
\hline
\end{tabular}

A possible explanation of the third-class structure, where companies with aggressive or competitive performance can be found, may be explained with the characteristics of the sample with more private than state-owned enterprises. Also, another potential explanation might be the similarity between aggressive and competitive performance. Both types of performance are characterized by high potential of the basic dimension the Industrial Strength (IS), and the differences are noted with aggressive strategic performance where the instability of the external environment is compensated with strong financial strength of the company, while the competitive performance is characterized by unstable external environment in a strong industrial segment. Although all companies from the research sample originate from the same geographical area (Republic of Serbia), they do not perceive equally the stability of external environment.

\section{Discussion}

The analysis of diagrams presented at Figure. 3-6 show that just a few of companies, regarding the selected criteria (size of the enterprise), have the value of the basic dimension Industrial Strenght (IS) over 3 - which is average value on the scale. Results for the basic dimension Financial Strenght (FS) show that for all of the SMEs (micro, small or medium enterprises) do not have value of FS more than 2 - which is less than average value. Therefore, in cases where an enterprise has an aggressive strategic performance (which is the best), this performance is characterized by average values and a relatively unstable position of the resulting vector (along the $\mathrm{x}$ axis). Environment uncertainty (ES) is, in all cases, also characterized with average values - up to -3 . This only indicates that any turbulence in the outside environment can easily endanger aggressive strategic performance of the company and put the company in a difficult position. These conclusions can be found in the research where the authors claim that the distance of the determined strategic position point from axis can be the indicator of the position pragmatism, but its closeness to the axis increases the axis sensitivity and necessitate its 
continuous screening. This means that if the point is close to the zero or one of the axes, a few changes in the subcriterion concept and conditions can change its score and consequently its strategic position (Sherafat et al., 2013). The relationship between strategic position, development strategies, strategy goal-setting, and defining the strategies for promoting every axis measure and the related strategies for improving the organization's performance from strategic perspective is an issue that has been rarely considered. The rational trend from the development step to strategy implementation has been suggested in this study.

Based on the obtained results, it can be observed that the model is applicable with all classification criteria for the companies from the research sample; therefore - it can also be applicable in the conditions of the developing country. The reason of model applicability to all selected companies probably lies in carefully selected and extended set of factors, i.e. indicators. In comparison to the basic, initial model (Rowe et al., 1994) that had proposed 24 factors, this model has 80 factors, some of which are estimated indirectly, through indicators.

Introduction of new competitors is, however, the crucial factor for aggressive strategic posture. Generic strategies are typical for this type of posture: market penetration, market development, product development, backward integration, forward integration, horizontal integration, conglomerate diversification, concentric diversification, and horizontal diversification. The competitive strategic posture is typical for industry/ business in relatively unstable environment. The organization with such a strategy is at competitive advantage and could acquire financial resources to increase marketing thrust, add to the sales force, and extend the product line. Such an organization could also invest in productivity, cut costs, or merge with a cash-rich organization. Financial strength is, however, of critical importance. Competitive strategies include backward, forward, and horizontal integration; market penetration; market development; product development; and joint ventures (Porter, 1997).

\section{Conclusion}

The results of the applied model clearly show that there is a possibility of precise definition of the strategic position of the company and the basis for adopting the appropriate strategy as well. Thoroughly analyzed factors, which changes have been observed, point to the critical points in a company. Naturally, there are certain disadvantages that can be overcome only by comprehensive analysis (model application to a large number of companies). This type of analysis can become the basis for application of a multiple factor method (and the basis for the other, more precise mathematical models), which can be used for defining precisely the set of factors and/or indicators that are considered within each basic dimension of the model for the assessment of strategic position of the company. This way, the questionnaire, which is the basis for application of the model, can become simpler and more concise, which is the purpose of this paper.

A company that needs to maintain its competitive advantage will choose the existing strategies that aim at maintaining its market share and profitability. This requirement cannot be satisfied only by preparing just one strategic plan for a company as a whole or for strategic business units. A strategic approach is defined based on the assessment of company's actual internal and external environment (all mentioned basic dimensions) as well as the values of the resulting model vector, and it will ensure that every management recognizes the significance of each factor necessary for maintenance or achievement of competitive strategic position.

The model can be improved when determining the relative importance of each of the proposed factors, that is, indicators. This significantly complicates the process of application of the SPACE model but does not diminish its quality as a detailed and comprehensive tool for strategy planning. Therefore, some of the methods of multiplecriteria decision-making can be used for this purpose - AHP method, for example, as Gurbuz showed in his paper (Gurbuz, 2013; Gurbuz, 2019).

Possible model constraints unequal representation of all categories of the company - most of the companies involved in the research are privately owned SMEs - which is in line with the economy of the Republic of Serbia which structure is the same as the ones of the European countries (dominance of SMEs in relation to big companies). The question remains whether this can be improved or changed, precisely because of that. Also, some additional model constraints are as follows: The directional vector could fall directly on an axis or could even go nowhere if the coordinate is $(0,0)$; Implications of the exact angle of the vector within a quadrant are unclear. (Allen \& Helms,2006). These were the limitations that were observed in the results of the research - the unstable position of the resulting vector and unexplained situation when the vector is along one of the axis of the coordinate system (Rumanti \& Syauta, 2013).

Furthermore, the model can be improved by using the Cost/Benefit analysis in order to evaluate the appropriate strategy alternative for defined strategic position. Further research could also include strategy implementation, strategic control, or strategic issues (globalization, IT culture, strategic change, etc.) that might occur in the SME (Safari et al., 2013).

The proposal to overcome the limitations of the SPACE model, especially when selecting the appropriate strategy, was also provided by Taranukha Yury, who, in his paper (Taranukha, 2016), proposed the dynamic approach and classification of the factor into 3 groups: the scale (level) of competition (local, national, international, global); market type (price-related, non-price, Figureht for leadership) and the type of firm behavior (defensive, competitive, aggressive - SPACE model).

The results of applying the model indicate the strategic position of the company and set of generic, recommended strategies for each position. Considering the fact that one quadrant, (one strategic position) can have several recommended strategies, certain authors have combined SPACE model and FUZZY logic, which was also used in the paper fuzzy TOPSIS, together with SWOT analysis. Such an aggressive strategic approach has the proposed SO strategies (strength-opportunities), and competitive approach - ST strategies (strength-threats). The improvement of SPACE model (that is, its modification) and the advantages of the fuzzy logics are also presented in 
the paper (Bafandeh et al., 2012). Fuzzy logic is a good method for decision making in SMEs, helping them to strengthen competitiveness through developing the information systems with flexible structure that allows to consider all changes in business environment, and to reduce the time-to market with the system (Shpolianska, et al., 2017).

Moreover, certain papers have proved that the SPACE model can also be used for the assessment of compliance of the project or its position with the company's position (whether the project complies with the position of the company or not). In any case, the results of the research show that the SPACE model is acceptable and applicable in developing countries as well (Borocki et al., 2018).

SUPER SPACE analysis assumes that the likelihood of the factors remaining at the same level in the future. Analysis presented in this paper showed how to combine value and significance of every factor and indicator of every basic dimension in order to define set of critical factors. Since the company has an influence on internal environment, this set should be consists only from the factors that belong to internal dimensions: Competitive Strength (CS) and Financial Strength (FS). The factor becomes critical if it its value is low but its significance for business activities is over average. This is presented through value of the GAP attribute. The company needs to estimate potential with which it overcome this situation and improve

\section{Acknowledgement}

The authors acknowledge the financial support of the Ministry of Education, Science and Technological Development of the Republic of Serbia, within Project No 47005.

\section{References}

Afriani, E., Dewi, F., \& Mulyati R. (2012). Strategic Management Implementation Fred R. David Concept at PT Indofood Sukses Makmur, Tbk. International Journal of Science and Research, 3(5), 608-614.

Allen, R. S., \& Helms, M. M. (2006). Linking strategic practices and organizational performance to Porter's generic strategies. Business Process Management Journal, 12(4), 433-454, https://doi.org/10.1108/14637150610678069

Bafandeh, Z., Alireza, A, Samad, N., \& Atashpeykar, H. (2012). A new Approach to SPACE Matrix. International Conference on Economics and Finance Research IPEDR, 40-44.

Belas, J., Rahman, A., Rahman, M. T., \& Schonfeld, J. (2017). Financial Constraints on Innovative SMEs: Empirical Evidence from the Visegrad Countries. Inzinerine Ekonomika-Engineering Economics, 2017, 28(5), 552-563, http://dx.doi.org/10.5755/j01.ee.28.5.18204

Benson, A., \& Henderson, S. (2005). UK leisure centres under best value: a strategic analysis. International Journal of Public Sector Management, 18 (3), 196-215, https://doi.org/10.1108/09513550510591515.

Benson, A., \& Henderson, S. (2011). A strategic analysis of volunteer tourism organizations. Service Industries Journal, 31(3), 405-424. https://doi.org/10.1080/02642060902822091

Borocki, J., Radisic, M., \& Stefanic, I. (2018). Space Analysis as a Tool for Internal Development Factors Measurement within Companies, Tehnicki vjesnik/Technical Gazette, 25(Suppl. 2), 404-410, https://doi.org/10.17559/TV20170921154744.

Boyd, B. K. (1991). Strategic planning and financial performance: A meta-analytic review. Journal of Management Studies, 28(4), 353-374, https://doi.org/10.1111/j.1467-6486.1991.tb00286.x.

Brews, P. J., \& Hunt, M. R. (1999). Learning to plan and planning to learn: Resolving the planning school/learning school debate. Strategic Management Journal, 20(10), 889-913, https://doi.org/10.1002/(SICI)1097-0266(199910)20:10 $<889::$ AID-SMJ60>3.3.CO;2-6 
Brunswicker, S., \& Vanhaverbeke, W. (2015). Open innovation in small and medium-sized enterprises (SMEs): External knowledge sourcing strategies and internal organizational facilitators. Journal of Small Business Management, 53(4), 1241-1263. https://doi.org/10.1111/jsbm.12120

David, F. (2011). Strategic management, concepts and cases. Prentice Hall, New Jersey

Derbaliev, S., \& Trpkova, M. (2011). Strategic planning practice in transition economies: Empirical evidence from the Macedonian context. Business and Economic Horizons, 4(1), 27-39, https://doi.org/10.5430/jms.v8n1p74.

Dibrell, C., Craig, J. B., \& Neubaum, D. O. (2014). Linking the formal strategic planning process, planning flexibility, and innovativeness to firm performance. Journal of Business Research, 67(9), 2000-2007. https://doi.org/10.10 16/j.jbusres.2013.10.011

Drucker, P. F. (1986). Management: Tasks, responsibilities, practices. Truman Talley Books, New York.

Fraley, C., \& Raftery, A. E. (2002). Model-based clustering, discriminant analysis, and density estimation. Journal of the American Statistical Association, 97(458), 611-631, https://doi.org/10.1198/016214502760047131.

Fuad, N., A. (2001). Strategic Planning Process in Developing Countries: The Case of United Arab Emirates Business Firms, International Journal of Applied Strategic Management, 1(2), 285-295.

Gica, O. A., \& Balint, C. I. (2012). Planning practices of SMEs in North-Western region of Romania-An empirical investigation. Procedia Economics and Finance, 3, 896-90. https://doi.org/10.1016/S2212-5671(12)00247-X

Ghobadian, A., O'Regan, N., Thomas, H., \& Liu, J. (2008). Formal strategic planning, operating environment, size, sector and performance. Journal of General Management, 34(2), 1-20. https://doi.org/10.1177/030630700803400201

Grant, R. M. (2003). Strategic planning in a turbulent environment: Evidence from the oil majors. Strategic Management Journal, 24(6), 491-517, https://doi.org/10.1002/smj.314

Griggs, H. E. (2002). Strategic planning system characteristics and organisational effectiveness in Australian small-scale firms. Irish Journal of Management, 23(1), 23-53.

Gurbuz, T. (2013). A Modified Strategic Position and Action Evaluation Matrix Method, International Multi Conference of Engineers and Computer Scientists, Hong Kong, 866-869.

Gurbuz, T. (2019). Strategy Formulation Using a Hybrid Multi Criteria Decision Making Approach for Strategic Position and Action Evaluation (SPACE) Matrix Method. Journal of Aeronautics and Space Technologies, 12(1), ISSN: 1304-0448).

Hlavacka, S., Ljuba, B., Viera, R., \& Robert, W. (2001). Performance implications of Porter's generic strategies in Slovak hospitals. Journal of Management in Medicine, 15(1), 44-66. https://doi.org/10.1108/02689230110386489

Kash, B. A., \& Deshmukh, A. A. (2013). Developing a Strategic Marketing Plan for Physical and Occupational Therapy Services: A Collaborative Project Between a Critical Access Hospital and a Graduate Program in Health Care Management. Health Marketing Quarterly, 30(3), 263-280, https://doi.org/ 10.1080/07359683.2013.814507

Kazemi, H., Mehraban N., \& Lynette, L. (1998). The SPACE Matrix: A tool for calibrating competition. Long Range Planning, 31(4), 549-559, https://doi.org/10.1016/S0024-6301(98)80048-4.

Kim, E., Nam, D., \& Stimpert, J. (2004). The applicability of Porter's generic strategies in the digital age: assumptions,conjectures, and suggestions. Journal of Management, 30(5), 569-89, https://doi.org/10.101 6/j.jm.2003.12.001.

Kimemia, F. M., Bwaisa, H., Muturi, W., \& Kihoro, J. (2017). Investigation Of The Adoption Of Strategic Planning By Small And Medium Sized Manufacturing Firms In Kenya. International Journal of Economics, Commerce and Management, 1(4), 116-225.

Kliestikova, J., Krizanova, A., Corejova, T., Kral, P., \& Spuchlakova, E. (2018). Subsidies to increase remote pollution?. Science and Engineering Ethics, 24(2), 755-767. https://doi.org/10.1007/s11948-017-9908-0.

Kozma, T. (2017). Cooperation in the supply chain network. Forum Scientiae Oeconomia, 5(3), 45-58. https://doi.org/ 10.23762/FSO_vol5no3_17_3.

Kraus, S., Harms, R., \& Schwarz, E. J. (2006). Strategic planning in smaller enterprises - new empirical findings. Management Research News, 29(6), 334-344, https://doi.org/10.1108/01409170610683851

Kraus, S., Schwarz, E. J., \& Harms, R. (2008). Strategic business planning and success in small firms. International Journal of Entrepreneurship and Innovation Management, 8(5), 381-396. https://doi.org/10.1504/IJEIM.2008.022311 
Jelena Borocki, Mladen Radisic, Włodzimierz Sroka, Jolita Greblikaite, Armenia Androniceanu. Methodology for Strategic...

Kraus, S., Reiche, B. S., \& Reschke, C. H. (2013). The role of strategic planning in SMEs: Literature review and implications, Conference proceedings of the Annual Meeting of the British Academy of Management, Oxford, UK, September 13-15

Li, X., \& Hamblin, D. J. (2003). The impact of performance and practice factors on UK manufacturing companies' survival. International Journal of Production Research, 41(5), 963-979. https://doi.org/10.1080/00207540210163937

Malekpour, S., Brown, R. R., De Haan, F. J. (2015). Strategic planning of urban infrastructure for environmental sustainability: understanding the past to intervene for the future. 46, 67-75. http://dx.doi.org/10.10 16/j.cities.2015.05.003

Miller, C. C., \& Cardinal, L. B. (1994). Strategic planning and firm performance: A synthesis of more than two decades of research. Academy of Management Journal, 37(6), 1649-1665, https://doi.org/10.2307/256804.

Mintzberg, H. (1994). Rethinking strategic planning. Part 1: pitfalls and fallacies. Long Range Planning, 27(3), 12-21, https://doi.org/10.1016/j.lrp.2013.01.001.

Mintzberg, H. (1994). Rethinking strategic planning. Part 2: new roles for planners. Long Range Planning, 27(3), 22-30, https://doi.org/10.1016/j.lrp.2013.01.001.

Moravcikova, D., \& Kliestikova, J. (2017). Brand building with using phygital marketing communication. Journal of Economics, Business and Management, 5(3), 148 -153, https://doi.org/10.18178/joebm.2017.5.3.503

Nomsa, S., \& Tebogo, I. (2017). Strategic planning in small and medium enterprises (SMEs): A case study of Botswana SMEs. Journal of Management and Strategy, 8(1), 74-13, https://doi.org/10.5430/jms.v8n1p74.

North, K., \& Varvakis, G. (2016). Competitive strategies for small and medium enterprises. Increasing Crisis Resilience, Agility and Innovation in Turbulent Times. Cham: Springer. https://doi.org/10.1007/978-3-319-27303-7

Nouri, J., Karbassi, R., \& Mirkia, S. (2008). Environmental management of coastal regions in the Caspian Sea. International Journal of Environmental Science and Technology, 5(1), 43-52. https://doi.org/10.1007/BF03325996

Parnell, J., Long, Z., \& Lester, D. (2015). Competitive strategy, capabilities and uncertainty in small and medium sized enterprises (SMEs) in China and the United States. Management Decision, 53(2), 402-431, https://doi.org/10.1108/MD-04-2014-0222.

Peel, M. J., \& Bridge, J. (1998). How planning and capital budgeting improve SME performance. Long Range Planning, $31(6), 848-856$.

Pietrasienski P., \& Slusarczyk B., (2015). Internationalization of small and medium enterprises - empirical research review on barriers to entry into foreign markets. Polish Journal of Management Studies, 11(1), 113-123.

Porter, M. E. (1979). How competitive forces shape strategy. Harvard Business Review, 57(2), 137-145.

Porter, M. E. (1997). Competitive strategy. Measuring Business Excellence, 1(2), 12-17, https://doi.org/10.1108/eb025476

Rajesh, K. S., Suresh, K. G., \& Deshmukh, S. G. (2008). Strategy development by SMEs for competitiveness: a review. Benchmarking: An International Journal, 15(5), 525-547, https://doi.org/10.1108/14635770810903132.

Robert, G. (1991). The resource-based theory of competitive advantage: Implications for strategy formulation. California Management Review, 363(3), 114-135, https://doi.org/10.2307/41166664.

Rowe, A., Mason, R., Dickel, K., Mann, R., \& Mockler, R. (1994). Strategic management: A methodological approach. Addison-Wesley Publishing, Toronto.

Rudder, L., \& Louw, L. (1998). The SPACE matrix: A tool for calibrating competition. Long Range Planning, 31(4), 549-559, https://doi.org/10.1016/S0024-6301(98)80048-4.

Rumanti, A. A., \& Syauta, J. K. (2013). Determining strategies based on strategic position analysis in small and medium enterprises. International Journal of Information and Education Technology, 3(4), 442-447, https://doi.org/ 10.7763/IJIET.2013.V3.315.

Saeed, E., Esmaeil, J., \& Yahyaeian L. (2013). Assessment and analysis Strategies according to Space matrix-case study: Petrochemical and banking industries in Tehran Stock Exchange (TSE). Procedia-Social and Behavioral Sciences 99, 893-901, https://doi.org/10.1016/j.sbspro. 2013.10.562.

Safari, H., Behrooz, A., Bazargani, H., \& Soleimani-Sarvestani M. H. (2013). Proposing a framework for strategic positioning using an integrated method. World Applied Programming, 3(4), 150-163.

Scrucca, L., Fop, M., Murphy, T. B., \& Raftery, A. E. (2016). Mclust 5: Clustering, Classification and Density Estimation Using Gaussian Finite Mixture Models. The R Journal, 8(1), 289-317. https://doi.org/10.32614/RJ-2016-021 
Sherafat, A., Yavari, K., Sayyed, M., Davoodi R., \& Bozorgzadeh, N. (2013). The application of Strategic Position \& Action Evaluation (SPACE) matrix in the organizational goals and strategies development. Journal of Applied Sciences Research, 9(4), 2666-2673.

Shpolianska, I., Dolzhenko, A., \& Glushenko, S. (2017). Fuzzy models of web services selection in the development of service-oriented information systems for small and medium enterprises. Ekonomicko-manazerske spectrum, 11(2), 64-75, Available at: dx.doi.org/10.26552/ems.2017.2.64-75. https://doi.org/10.26552/ems.2017.2.64-75

Sroka, W., \& Szanto, R. (2018). CSR and business ethics in controversial sectors: analysis of research results, Journal of Entrepreneurship. Management and Innovation, 14(3), 111-126. https://doi.org/10.7341/20181435

Sroka, W., \& Vveinhardt, J. (2018). Nepotism and favouritism in the steel industry: A case study analysis. Forum Scientiae Oeconomia 6(1), 31-45. https://doi.org/10.23762/FSO_VOL6NO1_18_4.

Stonehouse, G., \& Pemberton, J. (2002). Strategic planning in SMEs - some empirical findings. Management Decision, 40(9), 853-861. https://doi.org/10.1108/00251740210441072

Street, C. T., Gallupe, B., \& Baker, J. (2017). Strategic alignment in SMEs: Strengthening theoretical foundations. Communications of the Association for Information Systems: 40 (20), https://doi.org/10.17705/1CAIS.04020.

Sukcharoensin, S. (2018). Strategic Position of Bond Markets in ASEAN-5: Challenges and Directions for Development. DLSU Business \& Economics Review, 27(2), 23-34.

Suklev, B., \& Debarliev, S. (2012). Strategic planning effectiveness comparative analysis of the Macedonian context, Economic and Business Review, 14(1), 63-93.

Sebestova, J., Sperka, R., Malecka, J., \& Luczka, T. (2017). Co-working centres as a supportive network for cross border business cooperation. Forum Scientiae Oeconomia, 5(4), 23-34. https://doi.org/10.23762/FSO_VOL5NO4_17_2.

Taranukha, Y. (2016). The firm's competitive profile. Management in Russia and abroad, 1-8.

Tidd, J., Bessant, J., \& Pavitt, K. (2005). Managing innovation integrating technological, market and organizational change. John Wiley and Sons Ltd, New York, 50-53.

Valaei, N., Rezaei, S., \& Ismail, W. K. W. (2017). Examining learning strategies, creativity, and innovation at SMEs using fuzzy set qualitative comparative analysis and PLS path modeling. Journal of Business Research, 70, $224-233$. https://doi.org/10.1016/j.jbusres.2016.08.016

Walker, W., Haasnoot, M., \& Kwakkel, J., (2013). Adapt or perish: a review of planning approaches for adaptation under deep uncertainty. Sustainability 5 (3), 955-979. http://dx.doi.org/10.3390/su5030955.

The article has been reviewed. Received in October 2018; accepted in June 2019. 